\title{
O DESAFIO CURRICULAR DA EDUCAÇÃO FÍSICA ESCOLAR: SISTEMATIZAÇÕES DE UMA PESQUISA- AÇÃO NA ESCOLA PÚBLICA
}

\author{
THE CURRICULAR CHALLENGE FACED BY SCHOOL PHYSICAL EDUCATION: \\ SYSTEMATIZATION OF AN ACTION RESEARCH STUDY CONDUCTED IN A \\ PUBLIC SCHOOL
}

EL DESAFÍO CURRICULAR DE LA EDUCACIÓN FÍSICA ESCOLAR: SISTEMATIZACIONES DE UNA INVESTIGACIÓN-ACCIÓN EN LA ESCUELA PÚBLICA

Ivan Carlos Bagnara*, Paulo Evaldo Fensterseifer**

Palavras chave: Conhecimento Currículo. Educação Física.

\begin{abstract}
Resumo: Objetivando identificar os obstáculos que emergem durante o processo de elaboração curricular e compreender como os professores encaminham as soluções para eles, desenvolvemos, na perspectiva qualitativa, uma pesquisa-ação, da qual participaram dois professores de Educação Física. Os dados produzidos suscitaram cinco categorias para análise: seleção dos conteúdos, conhecimentos escolares, complexificação dos conteúdos, tempos escolares e aporte teórico. Ao analisá-las, pode-se concluir que assumir as responsabilidades inerentes ao trabalho docente possibilita ao professor, ao mesmo tempo, levantar problemas e forjar soluções, as quais devem ser propostas com o auxílio de todos os envolvidos no processo educativo, incluindo as instituições formadoras.
\end{abstract}

Keywords:

Knowledge.

Curriculum

Physical Education.

Palabras clave: Conocimiento.

Currículo.

Educación Física.
Abstract: In order to identify challenges emerging during the process of designing the curriculum and understanding how teachers seek solutions for them, we developed a qualitative action research study in which two Physical Education teachers participated. The data resulted in five categories for analysis: content selection, school knowledge, content complexity, school time, and theoretical input. When analyzing them, one can conclude that assuming the responsibilities inherent in teaching enables teachers both to point out problems and to forge solutions. These solutions should be proposed with the help of all those involved in the educational process, including educational institutions.

Resumen: Con el objetivo de identificar los obstáculos que emergen durante el proceso de elaboración curricular y comprender cómo los profesores encaminan las soluciones para los mismos, desarrollamos, en la perspectiva cualitativa, una investigación-acción con la participación de dos profesores de Educación Física. Los datos producidos suscitaron cinco categorías de análisis: selección de contenidos, conocimientos escolares, complejidad de los contenidos, tiempos escolares y aporte teórico. Así, se puede concluir que asumir las responsabilidades del trabajo docente posibilita al profesor, al mismo tiempo, plantear problemas y elaborar soluciones, las que deben ser propuestas con la ayuda de todos los involucrados en el proceso educativo, incluyendo, las instituciones formadoras.
*Instituto Federal de Educacão, Ciência e Tecnologia do Rio Grande do Sul (IFRS). Erechim, RS, Brasil. E-mail: ivan.bagnara@erechim.ifrs. edu.br

**Universidade Regional do Noroeste do Estado do Rio Grande do Sul (UNIJUI). ljuí, RS, Brasil. E-mail: fenster@unijui.edu.br

Recebido em: 15-05-2018 Aprovado em: 24-01-2018 Publicado em: 22-03-2019

DOI https://doi.org/10.22456/1982-8918.82888 (c) (i) (8) Licence 


\section{INTRODUÇÃOO}

Refletir acerca da elaboração curricular na Educação Física Escolar (EFE) sugere significativo esforço coletivo; afinal, por mais de um século, primeiramente a Ginástica e depois a Educação Física (EF) estão inseridas no contexto escolar e esse período não contribuiu com a configuração de uma tradição curricular que pudesse ajudar a guiar as ações, como é o caso de outras disciplinas escolares. Assim sendo, enfrentar o desafio curricular, tema central deste estudo, é fundamental para contribuir com a legitimação da EFE enquanto disciplina educativa.

A orfandade de uma tradição curricular pode ser explicada, em parte, por não ter sido possível, durante as últimas décadas, entre idas e vindas, vislumbrar um "horizonte comum", uma "razão de ser" para a EFE, muito provavelmente pelo incipiente enfrentamento acerca das ações pedagógicas na perspectiva de disciplina educativa. Tal hipótese é sustentada com base nos escritos de Gimeno Sacristán (2000, p. 101), para quem a construção curricular ocorre "no processo de configuração, implantação, concretização e expressão de determinadas práticas pedagógicas e em sua própria avaliação, como resultado das diversas intervenções que nele se operam". Porém, em diversos contextos, a EFE ainda tem sido desenvolvida, conforme afirmam González e Fensterseifer (2006) e Machado et al. (2010), sob a perspectiva do fenômeno de abandono docente/desinvestimento pedagógico, o que impacta negativamente 0 processo de instituição curricular.

Dessa forma, os professores de EF são desafiados a explicitar e organizar os conhecimentos ligados às práticas corporais, pensando na estruturação progressiva, níveis de complexidade e densidade crítica dos conteúdos e conhecimentos, ao longo da Educação Básica - EB (BRASIL, 2015), vinculado ao sentido da escola republicana e democrática'. Nessa linha de raciocínio, questionamos: de que maneira o professor que atua no contexto escolar enfrenta o desafio curricular da EFE? Quais são e como são enfrentados os obstáculos que emergem durante a elaboração de um currículo para a EFE, concebendo-a como uma disciplina educativa?

Geralmente, quando há o desafio de enfrentar uma problemática até então inovadora, em que a maioria dos elementos necessários para tal enfrentamento não estão dados pela tradição, é comum encontrar número significativo de dificuldades e entraves para a materialização do proposto. Nesse sentido, na empreitada de estruturar um projeto curricular para a EFE na perspectiva de uma disciplina educativa, justamente por não ser algo dado pela tradição, é preciso tomar algumas decisões que podem ser consideradas inéditas no contexto, objetivando dar conta da elaboração de um projeto curricular conectado à intencionalidade (aspectos políticos ${ }^{2}$ ) da educação escolar, explicitada nos documentos escolares. Em outras palavras: a própria elaboração de um projeto curricular para a EFE se manifesta como uma tarefa de proporções gigantescas, justamente porque a EFE, nessa perspectiva, necessita adentrar em debates conceituais e críticos, abandonando a ideia de atividade, adotando a forma de um componente curricular com saberes específicos a ensinar. Com base na problemática posta, objetivamos identificar os obstáculos que emergem durante o processo de elaboração curricular e compreender como os professores encaminham as soluções para os distintos entraves.

1 Conforme González e Fensterseifer (2009) e Bagnara e Fensterseifer (2017).

2 No mesmo sentido de Brasil (2015; 2016) e Bagnara e Fensterseifer (2017). 


\section{PERCURSO METODOLÓGICO}

Este trabalho resulta de uma pesquisa-ação desenvolvida na perspectiva qualitativa. A pesquisa-ação consiste num método que procura, essencialmente, elucidar problemas sociais e técnicos, de relevância científica, por meio de grupos compostos por pesquisadores, membros da situação-problema e demais atores e parceiros interessados na resolução dos problemas levantados, pois a pesquisa-ação contém um "compromisso social e científico" (THIOLLENT, 2011, p. 09).

No âmbito deste estudo, o principal foco foi analisar o "processo" da pesquisa-ação e não o "produto da mudança" proporcionada pela ação da pesquisa. Deste "movimento" participaram, voluntariamente, dois professores de EF (Ivan e Patric ${ }^{3}$ ) concursados e nomeados, docentes nos anos finais do ensino fundamental em uma escola municipal, localizada numa cidade com cerca de cem mil habitantes, da região Norte do Estado do RS. A obra Afazeres da Educação Física na escola: planejar, ensinar, partilhar, de González e Fraga (2012) constituiu-se como a base teórica da pesquisa, que teve duração de um ano, totalizando 16 encontros.

A pesquisa-ação consistiu no enfrentamento dos desafios políticos, curriculares e didáticos, buscando instituir a EFE como uma disciplina educativa, um componente curricular legítimo. Ao longo da pesquisa, os professores conceberam na escola uma "nova" EF que, antes desenvolvida na perspectiva de "atividade", foi transformada, a partir da pesquisa-ação, em uma disciplina educativa. São os dados produzidos ao longo do enfrentamento do desafio curricular que constituem o corpus deste estudo.

A produção de dados foi realizada de duas formas: anotações em diário de campo e elaboração de narrativas docentes. Com relação ao diário de campo, as anotações foram realizadas em um caderno específico. Em alguns momentos, se referiam às interpretações do pesquisador acerca dos debates; em outros, foram constituídas por transcrições literais de falas dos participantes. Optamos por, além do diário de campo, solicitar a elaboração de narrativas docentes. A elaboração de narrativas permite ao participante a experiência da reflexão e da constante "autointerrogação". Para Molina e Molina Neto (2010, p. 168):

\footnotetext{
É por meio do exercício da narrativa que podemos identificar, organizar e nomear os significados que atribuímos a inúmeros fatos que vivemos mediante os quais podemos reconstruir as diversas compreensões que temos sobre nós mesmos. É um valioso instrumento para qualificar nossas reflexões de modo contextualizado e, como resultado, temos a possibilidade de ressignificar o vivido.
}

Os dados foram analisados através do método de análise de conteúdo proposto por Bardin (2011). A direção da escola municipal assinou o Termo de Autorização de Participação Institucional e os participantes assinaram o Termo de Consentimento Livre e Esclarecido. A pesquisa foi submetida ao Comitê de Ética, sendo aprovada sob o Parecer Consubstanciado de número 1.148.600. O estudo seguiu as normas para pesquisa envolvendo seres humanos, e a participação, tanto dos sujeitos como da instituição, ocorreu de forma voluntária.

\section{EDUCAÇÃO FÍSICA E CURRÍCULO: INSTITUINDO O “NOVO” NA ESCOLA}

O fato de desenvolver a EFE de acordo com os marcos legais (componente curricular), atendendo aos avanços teóricos da área que a concebem como uma disciplina com saberes 
a ensinar e conhecimentos específicos a produzir, traz à tona algumas questões novas ou velhas, mas que necessitam de uma forma de abordagem inovadora, pois, "[...] a partir de agora estaremos fazendo outras coisas, além de unicamente as atividades ligadas à prática corporal" (PROFESSOR PATRIC), o que remete a um enfrentamento com a tradição da EF. Durante a elaboração curricular, os professores Patric e Ivan depararam com vários elementos, os quais estão configurados em cinco categorias de análise: seleção dos conteúdos, conhecimentos escolares, complexificação dos conteúdos, tempos escolares e aporte teórico.

Selecionar os conteúdos que seriam estudados, apesar da aparente simplicidade, inicialmente, se constituiu em algo complexo e implicou levar em conta algumas questões: "O que ensinar? O que não ensinar? Por que ensinar 'isso' e não 'aquilo'? Quais seriam os critérios que determinariam os conteúdos a serem contemplados no projeto curricular? Qual seria o ponto de partida e aonde se pretendia chegar?" (DIÁRIO DE CAMPO). Abordar esses dilemas foi algo mais complexo do que o imaginado, pois estava havendo "interferência das preferências e habilidades pessoais na seleção e organização dos conteúdos" (DIÁRIO DE CAMPO).

Elencar os conteúdos de preferência pode ser entendido como algo até certa medida natural, pois o professor, muitas vezes, se pauta pela segurança que o conhecimento acerca de algo Ihe proporciona para tomar suas decisões. Ao mesmo tempo em que pode ser considerado natural, em outra perspectiva, pode ser um obstáculo, pois acaba por criar uma espécie de "roda viva" em que os conteúdos acabam por se repetir, se reproduzir, sem ressignificação, problematizações ou novas contextualizações. Essa "naturalização", ou "parar de pensar sobre", provoca uma reprodução acrítica dos conteúdos. Assim, na ausência de uma tradição curricular, a dimensão subjetiva se avoluma e, muitas vezes, os gostos pessoais do professor acabam por determinar o que acontece (ou não acontece) na EFE.

Ao refletir sobre a problemática, pensando numa perspectiva republicana, é preciso evitar que as preferências e habilidades pessoais interfiram na seleção dos conteúdos de estudo. "Foram decisões difíceis, afinal, quando pensávamos nas possibilidades, ao mesmo tempo que queríamos dar conta de tudo, tínhamos a noção de que não poderíamos" (PROFESSOR IVAN). Assim, num primeiro momento, a opção foi elencar a maior quantidade de práticas corporais sistematizadas, divididas nos grupos de conteúdos sugeridos por González e Fraga (2012): esporte, ginástica, jogo motor, luta, práticas corporais expressivas (dança e expressão corporal), atividades aquáticas e práticas corporais junto à natureza.

Devido ao grande número de conteúdos elencados e à impossibilidade de abordar todos, a seleção "foi realizada sempre pensando em aliar a vida escolar com a vida fora da escola dos estudantes" (PROFESSOR PATRIC). Nessa perspectiva, optou-se pelos grupos de conteúdos elencados anteriormente, com exceção das atividades aquáticas, acrescido dos conhecimentos relacionados às práticas corporais urbanas, haja vista que algumas delas fazem parte do contexto social dos estudantes.

Após selecionar os conteúdos, era preciso pensar sua tematização de forma alargada e em distintas perspectivas, possibilitando a produção de conhecimentos poderosos, que, para Young (2007), não é o conhecimento dos poderosos, mas refere-se ao que o conhecimento pode fazer, como, por exemplo, fornecer explicações confiáveis ou novas formas de se pensar a respeito do mundo. Nesse sentido, pensar nas alternativas possíveis evidenciou "dificuldades com os conteúdos menos 'tradicionais' da EFE. Inclusive falta de conhecimento sobre eles" 
(DIÁRIO DE CAMPO). O professor Patric afirma: "Encontrei dificuldades em estruturar os conteúdos que não são muito do meu conhecimento, como, por exemplo, a ginástica e a dança". Essa afirmação permite pensar que o processo de elaboração curricular, em muitos casos, pode ser tomado como um tempo e espaço que o professor possui para produzir conhecimento para "consumo próprio", para estudar ("formação em serviço").

Pensar na escolha, estruturação e compreensão dos conteúdos é determinante para a EFE, pois, conforme afirma Gariglio (2013, p. 122), "os professores têm responsabilidades especiais em relação ao conhecimento do conteúdo, atuando como primeira fonte para a compreensão da matéria pelos estudantes". A maneira como essa compreensão é comunicada transmite o que é essencial e o que é periférico sobre o assunto. Neira e Nunes (2009) alertam que a escolha dos conteúdos não deve ser realizada de forma arbitrária e, tampouco, ficar à mercê de interesses particulares. Indicam ainda que a decisão sobre os conteúdos a serem ensinados deve ser pautada pela leitura e interpretação da realidade e promover articulações em diferentes níveis de discussão. 0 professor Ivan aponta os aspectos que nortearam as decisões:

[...] optamos por analisar, primeiramente, quais conteúdos estariam ligados ao 'saber para praticar' e, depois, quais estariam ligados ao 'para conhecer'. Nessa lógica, decidimos que os esportes coletivos tradicionais estariam elencados no eixo 'para praticar' por vários motivos: disponibilidade de materiais e espaço físico, envolvimento dos estudantes com esses conteúdos e o nosso próprio conhecimento sobre eles. Depois, elencamos os conteúdos que estariam no patamar do 'para conhecer'. No momento desta seleção, decidimos por levar em conta a possibilidade de vivência prática.

Os conteúdos ligados ao "saber para praticar", para González e Fraga (2012), têm maior tempo destinado ao estudo. São tematizados em uma unidade didática maior, pois a EFE deverá potencializar aos estudantes o desenvolvimento de competências e aprendizados básicos para que consigam, de forma proficiente, praticar o mesmo entre os amigos, de forma recreativa, com capacidade de organização para isso. Os conhecimentos ligados ao "praticar para conhecer" têm menor tempo destinado ao estudo em cada unidade didática, pois o objetivo é "apresentá-los" aos estudantes, que, caso se interessem por eles, podem buscar outras formas de aprendizagem com o intuito de auxiliá-los a praticar de forma proficiente. Mesmo na dimensão do "praticar para conhecer", o estudante vivenciará e experimentará o conteúdo; entretanto, o tempo de vivência dificilmente permitirá a prática proficiente.

Para Gariglio (2013), a seleção dos conteúdos esportivos como os principais a serem estudados, como ocorreu no caso desta pesquisa, se dá devido à satisfação proporcionada ao trabalho do professor, às facilidades para operar as práticas de ensino, à maior familiaridade com o trabalho esportivo, ao menor esforço em convencer os alunos da importância de conteúdos mais distantes na vida cultural deles e à sensação de maior conforto em virtude da forma de organização dos espaços, materiais e ambientes da escola, geralmente adaptados à prática esportiva.

Especificamente no desenvolvimento deste estudo, o critério de possibilitar a vivência prática (fazer), mesmo que de forma superficial, orientou a tomada de decisões, pois um dos três elementos fundamentais e comuns a todas as práticas corporais possui como aspecto central o movimento corporal (BRASIL; 2016; 2017; FENSTERSEIFER et al., 2013; GONZÁLEZ; FRAGA, 2012; GONZÁLEZ; FENSTERSEIFER, 2010). "Esse foi um dos motivos pelos quais 
as atividades aquáticas não foram contempladas no currículo, afinal, no nosso contexto, não há possibilidade de vivência prática" (DIÁRIO DE CAMPO).

A opção por estudar os conteúdos que possibilitem, mesmo que minimamente, a vivência prática pode ser entendida como paradoxal. Ao mesmo tempo em que não oportuniza aos estudantes conhecer, pelo menos teoricamente, alguns conteúdos considerados menos tradicionais e que fazem parte da cultura corporal, possibilita a produção de conhecimentos e saberes menos abstratos, pois, por menor que sejam os tempos de experiência e a quantidade de vivências corporais, produzem conhecimentos e saberes únicos, com maior significância e potencial de empoderamento. Tematizar conteúdos que permitam a vivência prática potencializa, para Charlot (2009), construir referências e princípios associados a uma experiência vivenciada. Essa perspectiva é importante, pois, para Neira e Nunes (2009), é a experiência da aprendizagem que configura os conteúdos do ensino.

No que concerne às dimensões dos conhecimentos/saberes de cada conteúdo, a opção foi por organizá-los em duas dimensões: "saberes corporais e saberes conceituais, esta última na perspectiva de conhecimentos técnicos e críticos" (DIÁRIO DE CAMPO). Tendo Kunz (2005) como referência, González e Fraga (2012) denominam os saberes corporais como aqueles que se constroem com base na experiência sustentada no e pelo movimento corporal: refere-se ao saber-fazer, que se expressa na ação. González e Fensterseifer (2010) pontuam que os saberes produzidos pela experiência das manifestações corporais não podem ser substituídos pela reflexão conceitual sobre elas, da mesma forma que os conhecimentos originados na vivência da prática não substituem as ferramentas cognitivas fornecidas pelos conceitos.

Na dimensão dos saberes conceituais, são estudados os conceitos sobre as práticas corporais: o "saber" acerca do "fazer". Para González e Fraga (2012), esses saberes são relativos ao conjunto de dados e conceitos que descrevem e explicam diferentes aspectos das práticas corporais sistematizadas e se desdobram em conhecimentos técnicos e críticos. Os conhecimentos técnicos articulam os conceitos necessários à compreensão das características e do funcionamento das práticas corporais numa dimensão de caráter operacional. Enquanto os críticos tratam da inserção das práticas corporais em determinados contextos socioculturais, lidam com temas que permitem analisar as manifestações da cultura corporal numa perspectiva ética e estética relativa à época e à sociedade que as geraram, às razões de sua produção e transformação, à vinculação local, nacional e global.

Nessa linha de trabalho, "a maior dificuldade foi organizar os conhecimentos críticos" (DIÁRIO DE CAMPO). Para o professor Patric, "a maior dificuldade tem relação com os conhecimentos conceituais, mas, principalmente, os críticos a serem trabalhados em cada ano". O próprio professor Patric identificou a possível origem desse problema. Para ele, "na formação acadêmica o foco era voltado para atividades corporais, não para atividades críticas, conceituais". Esse fato pode explicar em parte as dificuldades encontradas para sistematizar os saberes conceituais.

Sobre a relação entre a Fl e a estruturação curricular, o professor Patric afirma: "Com relação aos esportes mais praticados na escola e em nosso contexto, não tivemos muitas dificuldades em estruturar a parte corporal, pois já temos um certo conhecimento sobre esse conteúdo e, também, porque a formação foi basicamente voltada para esse aspecto". Gariglio (2013) endossa essa perspectiva, afirmando que essa questão tem estreita relação com a maneira como a Fl ocorreu, ou até mesmo pela comodidade que pode haver em permanecer na 
"zona de conforto" ao invés de se aventurar numa "zona de fronteira". Assim, pode-se presumir que, além dos aspectos formativos e dos problemas da alçada da gestão escolar, os atributos pessoais do professor também interferem na análise deste aspecto.

Além da dimensão esportiva, outro ponto de destaque se refere à forma como os conteúdos foram estudados na FI, o que indica que a EFE tem sido desenvolvida tomando os aprendizados da FI como mote, ou seja, seguindo a mesma lógica de trabalho da FI (dicotomia teoria e prática).

Tínhamos que dominar a técnica, algumas variações táticas e realizá-las de forma correta, mas muito pouco sabendo em como desenvolver cada conteúdo na escola com os estudantes das mais variadas séries e idades. Do ponto de vista conceitual, tínhamos como enfoque saber da história, das regras e conceituar as técnicas (PROFESSOR IVAN).

A situação descrita pode ser uma das causas para as dificuldades encontradas no momento de sistematizar os conteúdos. Segundo o professor Ivan:
[...] os conteúdos do eixo dos saberes corporais foram mais fáceis de organizar. Tivemos um pouco de dificuldade em alguns conteúdos, como dança, ginástica e lutas, mas no geral foi tranquilo. Encontramos maiores dificuldades em elencar os conteúdos do eixo dos saberes conceituais técnicos e enormes dificuldades em pensar os conhecimentos críticos. Somente foi possível organizar os saberes conceituais técnicos e críticos com a ajuda de materiais de apoio teórico.

Esse é um fenômeno que revela as deficiências da FI no que se refere à "teoria" (saberes conceituais), dado que, na constituição do projeto curricular, no exercício de elencar os conteúdos, essa teoria deveria estar "operando" e auxiliando a elaboração dele, mas como parece que a teorização dos diferentes temas na FI tem acontecido de forma rasa, ela também se colocou como um problema. Essa situação pode ser ainda mais problemática, se for considerado que é o caráter universal abstrato da teoria que permite o diálogo com os diferentes temas em distintos contextos. Dessa forma, parece não ser possível produzir conhecimentos poderosos e significativos sem tematizar os saberes conceituais de forma multidimensional ${ }^{4} \mathrm{e}$ com maior complexidade ao longo dos anos escolares. Esse é um problema sério na EFE, pois na visão de Neira e Nunes (2009, p. 246) citando Kincheloe e Steinberg (1999)5 , a "carência de atividades de aprofundamento fará persistir a cegueira cultural que impede o reconhecimento das relações sociais do mundo vivencial". E esse é um entrave considerável quando se pretende estruturar um componente curricular que contribua com a radicalização do potencial republicano e democrático da sociedade a partir de conhecimentos escolares poderosos.

Acerca do aprofundamento e complexificação dos conteúdos, González e Fraga (2009) e Fensterseifer et al. (2013) afirmam que é preciso localizá-los e contextualizá-los pelo menos em três níveis: contextualização sincrônica, em que uma prática corporal sistematizada deve ser analisada em relação à época e à sociedade que a geraram; contextualização diacrônica, em que se considera o objeto cultural no eixo do tempo; e, por fim, uma contextualização contemporânea, que considera a inserção da prática corporal e suas representações sociais na atualidade da região, do país e do mundo.

Outro obstáculo surgido relaciona-se à "falta de noção do tempo necessário para tematizar os conhecimentos, principalmente os conceituais críticos e técnicos" (DIÁRIO DE

\footnotetext{
4 Na perspectiva da Base Nacional Comum Curricular (2017), por exemplo.

5 KINCHELOE, J. L.; STEINBERG, S.R. Repensar el multiculturalismo. Barcelona: Octaedro, 1999, apud Neira e Nunes (2009).
} 
CAMPO). Esse elemento pode ser considerado um problema, pois, num projeto inovador, geralmente não se tem noção das reais necessidades de tempo. Para estipular um tempo adequado, é necessário ao professor, antes de mais nada, analisar os objetivos educativos propostos. De certa forma, pensar na quantificação, sistematização e complexificação de conteúdos para o novo projeto acarretou como dúvida: "Será que conseguiremos desenvolver todos os conteúdos da forma como planejamos, com a quantidade de aulas que foram destinadas a cada um e atingindo os objetivos?" (PROFESSOR PATRIC).

Tratar de elaborações curriculares, de certa forma, é algo que pode ser pensado pela lógica do gerúndio, ou seja, é fazendo, analisando, testando, experimentando as proposições, que o currículo vai se constituindo e se solidificando. Ao se investir nesse percurso, ao longo dos anos, pode-se tornar possível qualificar e potencializar respostas para muitas questões. $\mathrm{Na}$ verdade, sempre que se está experimentando algo novo correm-se riscos. No caso da EFE, parece válido correr riscos, pois é também na tentativa, na experimentação e na reflexão sobre as ações que se oportuniza um "pensar alargado" que, por sua vez, pode propiciar as adequações entendidas como necessárias para se avançar com uma nova proposta. Em outras palavras: a análise recursiva sobre o fazer pedagógico e sobre a prática social permite ao professor encontrar subsídios para repensar e qualificar a ação docente e reestruturar 0 projeto educativo.

Entendemos a análise do fazer pedagógico, na perspectiva de prática social, como um ponto nevrálgico na tarefa de potencializar uma prática educativa inovadora na EF. Essa hipótese pode ser sustentada pelo fato de que os professores de EF, muitas vezes, veem a produção teórica como algo distante de sua prática pedagógica (dicotomia teoria e prática). Assim sendo, ao professor é necessário levar em consideração a sabedoria adquirida com a prática, com a experiência docente (TARDIF, 2014) e, num constante e recursivo diálogo com os saberes teóricos referenciais, estabelecer o que Gariglio e Borges (2014) chamam de epistemologia da prática docente.

De certa forma, esse foi o "movimento" efetivado na pesquisa. 0 estudo foi realizado com constante diálogo entre a reflexão acerca da prática realizada e os referenciais teóricos que sustentaram o processo. Para o professor Patric, "[...] com base em alguns livros, conseguimos estruturar melhor os objetivos e conteúdos a serem desenvolvidos em cada ano". O professor Ivan afirma ter "convicção de que, se não fosse pela obra de apoio e outras consultas que fizemos, pelas inúmeras conversas entre nós e com outros professores, não teríamos estruturado a proposta da forma como fizemos". Tratar do aspecto ligado ao aporte teórico na disciplina de EF é algo relevante, pois parece-nos que, na maioria dos contextos, não é comum encontrar professores de EF envoltos em livros, artigos e realizando pesquisas para qualificar sua prática docente, o que, ao mesmo tempo, é um aspecto paradoxal e intrigante. Essa perspectiva permite pensar, hipoteticamente, que se a questão do aporte teórico não for enfrentada na e pela $\mathrm{Fl}$, o professor tende a se movimentar somente pela perspectiva da prática, pois ele poderia evidenciar dificuldades em estabelecer referências teóricas para avançar nas questões em debate. Esse "buraco" formativo, de certa forma, reforça a ideia de que o professor de EF, em muitos casos, se move pela lógica "aplicacionista" do conhecimento, o que o mantém na sua condição de "menoridade". 


\section{CONCLUSÃO}

O enfrentamento curricular realizado evidenciou entraves e decisões, os quais necessitavam de respostas, até certo ponto, novas e imediatas. Como destacado no texto, muitos dos aspectos levantados não foram problematizados pela $\mathrm{FI}, 0$ que não isenta 0 professor de enfrentá-los. Acerca da $\mathrm{FI}$, entendemos que ela não pode ser responsabilizada pela resolução dos problemas do egresso como um a priori; contudo, compreendemos que ela não pode ficar alheia ao que acontece (ou não acontece) na EFE.

As maiores dificuldades se manifestaram no momento de sistematizar os conteúdos de menor tradição recente na área, como ginástica, dança e lutas, muito por conta do superficial conhecimento sobre eles. Além destes, até mesmo para os conteúdos mais tradicionais (esporte), houve dificuldades para sistematizar os conhecimentos conceituais, principalmente na dimensão crítica. Os professores atribuem esse fato à $\mathrm{FI}$, que, ao não problematizar essa dimensão, acabou por não chamar a atenção para a relevância desses saberes.

A pesquisa-ação como a desenvolvida neste caso pode ser considerada como um tempo e espaço destinado para formação em serviço, pois foi pautada por momentos de estudos, discussões e elaborações. Os próprios participantes endossam essa compreensão ao atribuir o êxito na elaboração curricular aos referenciais teóricos e aos debates, análises e reflexões realizadas, fato que, apesar de significativo e enaltecido (devido à crise no contexto educacional brasileiro), entendemos como intrínseco à docência e ao trabalho do professor.

Ao encaminharmos as palavras finais deste texto, fica a frágil certeza de que, enquanto professores, precisamos assumir as responsabilidades e obrigações inerentes ao trabalho docente. Isso possibilita, ao mesmo tempo, levantar problemas e pensar em soluções, que além de mobilizarem os professores, devem ser forjadas com o auxílio de todos os envolvidos no processo educativo: equipe pedagógica da escola, responsáveis pelo sistema educacional e as instituições formadoras. Caso contrário, provavelmente, a educação escolar, em diversos contextos, continuará órfã de conhecimentos poderosos acerca das práticas corporais.

\section{REFERÊNCIAS}

BAGNARA, Ivan Carlos; FENSTERSEIFER, Paulo Evaldo. Formação Inicial em Educação Física: tematizando um contexto com muitos desafios. In: SALÃO DO CONHECIMENTO. JORNADA DE PESQUISA, 22, 2017. Anais [...]. ljuí, RS: Unijuí, 2017. Disponível em: https://publicacoeseventos. unijui.edu.br/index.php/salaoconhecimento/article/view/7734/647. Acesso em: 8 jan. 2018.

BARDIN, Laurence. Análise de Conteúdo. Ed. rev. ampl. São Paulo: Edições 70, 2011.

BRASIL. Ministério da Educação. Secretaria de Educação Básica. Base Nacional Comum Curricular. 1를. versão. Brasília, 2015.

BRASIL. Ministério da Educação. Secretaria de Educação Básica. Base Nacional Comum Curricular. $2^{\underline{a}}$ versão. Brasília, 2016.

BRASIL. Ministério da Educação. Secretaria de Educação Básica. Base Nacional Comum Curricular. Versão homologada. Brasília, 2017. 
CHARLOT, Bernard. Ensinar a Educação Física ou ajudar o aluno a aprender seu corpo-sujeito? In: DANTAS JUNIOR, Hamilcar Silveira; KUHN, Roselaine; RIBEIRO, Sérgio Dorenski Dantas (org.). Educação Física, esporte e sociedade: temas emergentes. São Cristóvão: Editora da UFS, 2009. p. 231-246.

FENSTERSEIFER, Paulo Evaldo et al. Educação Física nas avaliações em larga escala brasileira: balanço e desafios. In: BRASIL. Avaliações da Educação Básica em debate: ensino e matrizes curriculares de referência das avaliações em larga escala. Brasília: Instituto Nacional de Estudos e Pesquisas Educacionais Anísio Teixeira, 2013. p. 357-386.

GARIGLIO, José Ângelo. Fazeres e saberes pedagógicos de professores de Educação Física. ljuí: Unijuí, 2013.

GARIGLIO, José Ângelo; BORGES, Cecília. Saberes docentes. In: GONZÁLEZ, Fernando Jaime; FENSTERSEIFER, Paulo Evaldo. (org.). Dicionário crítico de Educação Física. 3. ed. ljuí: Unijuí, 2014. p. 586-590.

GIMENO SACRISTÁN, José. 0 currículo: uma reflexão sobre a prática. 3. ed. Porto Alegre: Artmed, 2000.

GONZÁLEZ, Fernando Jaime; FENSTERSEIFER, Paulo Evaldo. Educação Física e cultura escolar: critérios para identificação do abandono do trabalho docente. In: CONGRESO DE EDUCACIÓN FÍSICA: REPENSANDO LA EDUCACIÓN FÍSICA, 2006, Córdoba. Actas del Congreso de Educación Física: Repensando la Educación Física. Córdoba: Ipef, 2006. p. 734-746.

GONZÁLEZ, Fernando Jaime; FENSTERSEIFER, Paulo Evaldo. Entre o "não mais" e o "ainda não": pensando saídas do "não-lugar" da EF escolar I. Cadernos de Formação RBCE. v. 1, n. 1, p. 9-24, set. 2009. Disponível em: http://revista.cbce.org.br/index.php/cadernos/article/ download/929/539. Acesso em: 15 mar. 2014.

GONZÁLEZ, Fernando Jaime; FENSTERSEIFER, Paulo Evaldo. Entre o "não mais" e o "ainda não": pensando saídas do "não-lugar" da EF escolar II. Cadernos de Formação RBCE. v.1, n. 2, p. 10-21, mar. 2010. Disponível em: http://rbce.cbce.org.br/index.php/cadernos/article/ viewFile/978/561. Acesso em: 15 mar. 2014.

GONZÁLEZ, Fernando Jaime; FRAGA, Alex Branco. Referencial curricular de Educação Física. In: RIO GRANDE DO SUL. Secretaria de Estado da Educação. Departamento pedagógico (org.). Referencias curriculares do Estado do Rio Grande do Sul: Linguagens, códigos e suas tecnologias: Arte e Educação Física. Porto Alegre: SE/DP, 2009. v. 2, p. 111-181.

GONZÁLEZ, Fernando Jaime; FRAGA, Alex Branco. Afazeres da Educação Física na Escola: planejar, ensinar, partilhar. Erechim: Edelbra, 2012.

KUNZ, Elenor. Se-movimentar. In: GONZÁLEZ, Fernando Jaime; FENSTERSEIFER, Paulo Evaldo (Orgs.). Dicionário crítico de Educação Física. ljuí: Editora Unijuí, 2005. p. 608-610.

MACHADO, Thiago da Silva et al. As práticas de desinvestimento pedagógico na Educação Física Escolar. Movimento, v. 16, n. 02, p. 129-147, abr./jun. 2010. Disponível em: http://seer. ufrgs.br/index.php/Movimento/issue/view/901. Acesso em: 23 mar. 2016.

MOLINA, Rosane Maria Kreusburg; MOLINA NETO, Vicente. Pesquisar com narrativas docentes. In: MOLINA NETO, Vicente; TRIVIÑOS, Augusto N. S. (org.) A pesquisa qualitativa na Educação Física: alternativas metodológicas. 3. ed. Porto Alegre: Sulina, 2010. p. 165-176. 
NEIRA, Marcos Garcia; NUNES, Mário Luiz Ferrari. Educação Física, Currículo e Cultura. São Paulo: Phorte, 2009.

TARDIF, Maurice. Saberes docentes e formação profissional. 16. ed. Petrópolis: Vozes, 2014.

THIOLLENT, Michel Metodologia da pesquisa-ação. 18. ed. São Paulo: Cortez, 2011.

YOUNG, Michael. Para que servem as escolas? Educação e Sociedade, v. 28, n. 101, p. 12871302, set./dez. 2007. Disponível em: http://www.scielo.br/pdf/es/v28n101/a0228101.pdf. Acesso em: 13 set. 2015.

\section{Apoio:}

O presente trabalho foi realizado com apoio da Coordenação de Aperfeiçoamento de Pessoal de Nível Superior - Brasil (CAPES) - Código de Financiamento 001. This study was financed in part by the Coordenação de Aperfeiçoamento de Pessoal de Nível Superior - Brasil (CAPES) Finance Code 001. 